\title{
Change in diet in the period from adolescence to early adulthood: a systematic scoping review of longitudinal studies
}

Eleanor M. Winpenny ${ }^{*}$, Tarra L. Penney, Kirsten Corder, Martin White and Esther M. F. van Sluijs

\begin{abstract}
Background: Late adolescence to early adulthood is a period of lifestyle change and personal development which may influence dietary behaviour. Understanding dietary trajectories across this age range may help in targeting interventions appropriately. This scoping review aimed to assess how longitudinal change in diet is conceptualised and measured between the ages of 13 to 30 .

Methods: We searched Medline, SCOPUS, Embase, Psyclnfo (EBSCO), ASSIA, Sportdiscus, and Web of Science Core Collection (January 2016) using search terms combining diet outcomes, longitudinal methods and indicators of adolescent or young adult age. Titles and abstracts were screened and data extracted following published guidelines for scoping reviews. Data were analysed to summarize key data on each study and map availability of longitudinal data on macronutrients and food groups by age of study participants.

Results: We identified 98 papers reporting on 40 studies. Longitudinal dietary data were available on intake of energy, key macronutrients and several food groups, but this data had significant gaps and limitations. Most studies provided only two or three waves of data within the age range of interest and few studies reported data collected beyond the early twenties. A range of dietary assessment methods were used, with greater use of less comprehensive dietary assessment methods among studies reporting food group intakes.

Conclusion: Despite limited availability of longitudinal data to aid understanding of dietary trajectories across this age range, this scoping review identified areas with scope for further evidence synthesis. We identified a paucity of longitudinal data continuing into the mid and late twenties, variability in (quality of) dietary assessment methods, and a large variety of macronutrients and food groups studied. Advances in dietary assessment methodologies as well as increased use of social media may facilitate new data collection to further understanding of changing diet across this life stage.
\end{abstract}

Keywords: Diet, Adolescent, Young adult, Longitudinal, Trajectory

\footnotetext{
* Correspondence: ew470@cam.ac.uk

MRC Epidemiology Unit \& Centre for Diet and Activity Research (CEDAR),

University of Cambridge School of Clinical Medicine, Institute of Metabolic

Science, Cambridge Biomedical Campus, Box 285, Cambridge CB2 0QQ, UK
} 


\section{Background}

During adolescence and early adulthood, poor diet contributes towards immediate health risks, such as weight gain, inadequate bone mineralization and poor academic performance [1]. However, in addition, poor diets developed in childhood frequently persist into adulthood [2], influencing risk of chronic disease in later life including diabetes, cardio-vascular disease and certain cancers [3-5]. The period of late adolescence to early adulthood has been suggested as an important but overlooked age for establishment of long-term health behaviour patterns [6].

Adolescence is a period of rapid physiological and psychological development [7], while early adulthood has been described as 'demographically dense', characterised by transitions between different social roles [8]. In addition to further development of self-identity during this period [9], individuals experience major transitions during the adolescent to early adulthood period. These include changes in social environment and social influences, moving from family dependence towards stronger peer networks and development of intimate partner relationships. There may be changes in the home environment, with individuals often moving out of the family home to live independently, changes in school/work environment from secondary to further education and into employment and changes in financial circumstances, with individuals often achieving financial independence during this period. Many of these factors show associations with diet and eating behaviours in this age range [10-12].

Despite tracking of diet between childhood and adulthood [2], there is evidence to support the "habit discontinuity hypothesis" which states that behaviour change is more likely to be successful when a context change disrupts individuals' pre-existing habits [13, 14]. Adolescent to adult transitions may thus present opportunities for interventions to improve diet. In order to develop and target public health interventions most appropriately, it is important to understand underlying changes in diet throughout this period, the establishment of long-term dietary patterns, and factors that impact on changes in diet.

While a number of studies have reported on longitudinal changes in diet over the period from adolescence to early adulthood, the evidence is diverse in terms of the dietary measures of interest, methods of dietary assessment, age range of interest and frequency of followup [15-17]. The heterogeneous nature of this evidence can make systematic review and meta-analysis difficult, nevertheless a comprehensive overview of the literature is needed to provide an understanding of the data available and current knowledge on change in diet across this age range. The purpose of this work was to support this by conducting a systematic scoping review and synthesis to identify the range of available evidence and address the question: How is longitudinal change in diet conceptualised and measured in the period from adolescence to early adulthood (age 13-30)? Specifically, we aimed to: (1) map the cohorts providing data on longitudinal diet, by country, size, data collection period and method of dietary assessment used; (2) assess the evidence available across macronutrients and food groups; and (3) analyse the number of repeated measurements and age ranges covered by data on each macronutrient and food group. From this data synthesis we make recommendations for further systematic review and data collection to address questions concerning change in diet in this age range.

\section{Methods}

We carried out a scoping review following published guidelines [18-21], as shown in Table 1.

We registered the review on PROSPERO (ref: CRD42015030126).

We looked for prospective longitudinal data on dietary intake reported between mean ages of 13 and 30 years. While a consensus has not been reached on a definition of early adulthood, Rindfuss [8] suggested the 30th birthday as the end of the young adult years. Adolescence is defined by the World Health Organization (WHO) as ages 10 to 19 years [22], however we begin our review at age 13 years, since we are primarily interested in transitions occurring from mid-adolescence to early adulthood. This period includes that of 'emerging adulthood' which has been conceptualised as covering the period from age 18 to 25 years and postulated as a transitionary period between adolescence and full adulthood [23].

We searched Medline, SCOPUS, Embase, PsycInfo (EBSCO), ASSIA, Sportdiscus, and Web of Science Core Collection in January 2016 using search terms that combined diet outcomes, longitudinal methods and indicators of adolescent or young adult age range. Since this review was conducted in parallel with a partner review looking at change in physical activity (PROSPERO ref.:

\section{Table 1 Scoping review definition and methodology}

"A scoping review or scoping study is a form of knowledge synthesis that addresses an exploratory research question aimed at mapping key concepts, types of evidence, and gaps in research related to a defined area or field by systematically searching, selecting, and synthesizing existing knowledge." [21]

Stages of the scoping review methodology: [18]

1. Identifying the research question

2. Identifying relevant studies

3. Study selection

4. Charting the data

5. Collating, summarizing and reporting the results 
CRD42015030114), the search terms also included physical activity outcomes. The full search strategy as applied to Medline is shown in Additional file 1: Table S1. We also conducted additional hand searches; checking the reference lists of all included papers, and citation searches of key included papers which addressed the same research question as this review.

Three researchers (EW, KC, EvS) screened titles and abstracts of identified records against a set of inclusion and exclusion criteria (Table 2). Firstly, the researchers independently screened the same 500 records and compared their results in order to ensure consistency in deciding on study eligibility. This process was repeated 3 times until acceptable consistency was reached (93\% agreement between all three reviewers). The remaining titles and abstracts were then screened by one of the three researchers. Full texts of potentially eligible studies were retrieved, separated by behaviour of interest, after which the diet-related full text papers were assessed against the inclusion and exclusion criteria by two researchers (EW and TP) independently. There was 93\% initial agreement on inclusion/exclusion and discrepancies were resolved by discussion. Any remaining disagreements or uncertainties between the reviewers were resolved by discussion within the wider research team.

Data were extracted from each included study on the diet outcomes reported, together with details of the ages at which data were available, further details of the study population and context (the size of each cohort, country and period of data collection, the variation in age of the cohort at baseline), and the dietary assessment method used. Data extraction was undertaken by one researcher (EW) and checked by a second (TP). No formal quality assessment was undertaken following standard practice for scoping reviews [18].

Data were summarized to record the number of papers and studies retrieved by country and record key details extracted from each study, including the number of data points collected between mean ages of 13 and 30 and the mean age of the cohort at each data collection. We then focussed on mapping of data by macronutrients and food groups and, for each macronutrient or food group where 5 or more studies had reported data, graphed the availability of data from each study by mean age at each data collection point. We grouped data on foods and food groups under seven food groups. However, we note that the data collected by different studies is not always easily comparable. For example, within the category 'dairy' this includes both studies that report data on all dairy consumption, as well as studies reporting on consumption of specific dairy products such as milk or cheese.

\section{Results}

Searches identified a total of 21,402 records following the removal of duplicates. After initial screening of titles and abstracts, we considered 318 references for full text review for the current scoping review. One paper was added from additional citation searches of included articles (Fig. 1). In total, 98 papers were included which reported longitudinal data on dietary intake between the ages of 13 and 30.

Table 2 Inclusion and exclusion criteria for the review

\begin{tabular}{|c|c|c|}
\hline & Inclusion criteria & Exclusion criteria \\
\hline Setting & $\begin{array}{l}\text { Any country } \\
\text { Studies where specified data (see below) } \\
\text { was collected during or after } 1980\end{array}$ & Studies reporting on data collected prior to 1980 \\
\hline Participants & Those aged between 13 and 30 years, inclusive & $\begin{array}{l}\text { Those aged below } 13 \text { years of age or above } 30 \text { years of age } \\
\text { Participant groups selected based on a pre-existing health condition } \\
\text { (including obesity, eating disorders, malnutrition) or pregnancy } \\
\text { Studies where participants are only competitive athletes }\end{array}$ \\
\hline Outcomes & $\begin{array}{l}\text { A measure of diet, including: } \\
\text { - Energy intake } \\
\text { - Intake of macronutrients or micronutrients } \\
\text { - Intake of particular food groups }\end{array}$ & $\begin{array}{l}\text { Studies including no dietary outcomes } \\
\text { Studies reporting tracking of dietary behaviours only with no data on } \\
\text { absolute change in behaviour } \\
\text { Studies reporting solely on alcohol intake } \\
\text { Studies reporting on eating disorders or weight reduction behaviour } \\
\text { Studies reporting on diet quality indices or dietary patterns only }\end{array}$ \\
\hline Study type & $\begin{array}{l}\text { Longitudinal prospective quantitative studies, with data } \\
\text { reported including on specified outcomes at at least } \\
2 \text { time points (minimum } 1 \text { year apart) where mean age } \\
\text { of the cohort is between ages } 13 \text { and } 30 \text { inclusive }\end{array}$ & $\begin{array}{l}\text { Cross-sectional studies } \\
\text { Intervention studies/trial analyses } \\
\text { Case-control studies } \\
\text { Retrospective studies } \\
\text { Qualitative studies } \\
\text { Reviews }\end{array}$ \\
\hline Publication type & Journal article & $\begin{array}{l}\text { Conference abstract, study protocol, report, dissertation, book and } \\
\text { professional journal }\end{array}$ \\
\hline Language & English & All other languages \\
\hline
\end{tabular}




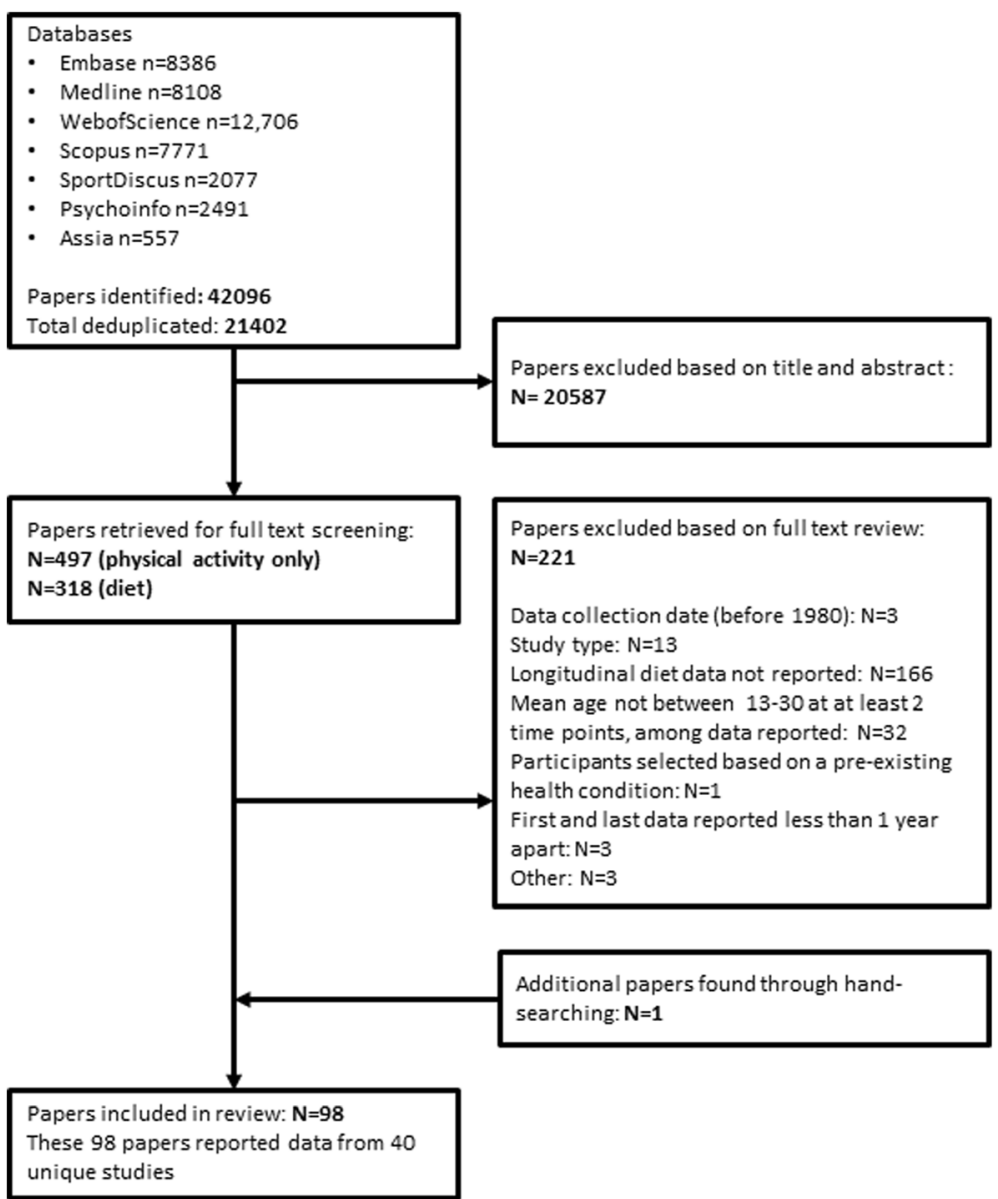

Fig. 1 PRISMA flow diagram

\section{Populations covered by study cohorts}

The 98 papers reported data from 40 unique studies. Table 3 presents an overview of the papers and studies by the cohort's country of origin. Studies were found reporting on data from 15 countries, with the largest number of studies $(n=15)$ originating from the US. A large number of papers were found from the Netherlands $(n=16)$, but these reported on data from only 2 studies. Similarly, 13 papers from Australia reported on 5 studies and 10 papers from Norway reported on 3 studies. From each of the remaining 11 countries we found only up to 4 papers. For each country we have listed the named studies in Table 3.

Table 4 presents further details on each study, including both named and unnamed studies. All studies reported on data from after 1980, as per our inclusion criteria, but most of the studies report on data collected more recently, from the 1990s and 2000s. Notable exceptions include the Amsterdam Growth and Health Longitudinal Study (AGHLS), the Coronary Artery Risk Development in Young Adults Study (CARDIA), the Northern Ireland Young Hearts Project $(\mathrm{YH})$ and the Oslo Youth Study
(OYS), for which data are reported which was collected in the 1980s.

Studies varied considerably in their sample size, ranging from 38 to 16,604 participants per wave. As can be seen in Table 4, of the larger studies with over 1000 participants $(n=13)$, many were based in the US, although other large studies include the 1993 Pelotas (Brazil) birth cohort study (Pelotas), the Birth to Twenty study (Bt20) from South Africa, the Cebu Longitudinal Health and Nutrition Study (CLHNS) from the Philippines, the Health and Behaviour in Teenagers Study (HABITS) from the UK and the Tracking Adolescents' Individual Lives Survey (TRAILS) from the Netherlands. Four studies had fewer than 100 participants in the waves reported. For each sample, where available, we report the standard deviation or range in baseline age in Table 4. Around half of the studies (where the degree of variation in baseline age is reported) described a cohort with a narrow age range, reporting a standard deviation in age of less than one year $(n=15)$. However, it should be noted that a number of cohorts have a much wider age range, for 
Table 3 Number of papers and studies retrieved by country

\begin{tabular}{|c|c|c|c|}
\hline Country & Papers & Studies & Named studies \\
\hline \multirow[t]{3}{*}{ Australia } & 13 & 5 & Adelaide Nutrition Study (ANS) \\
\hline & & & Raine Study (The Western Australian Pregnancy Cohort) (Raine) \\
\hline & & & Youth Eating Patterns study (YEP) \\
\hline Belgium & 1 & 1 & \\
\hline Brazil & 1 & 1 & 1993 Pelotas (Brazil) birth cohort study (Pelotas) \\
\hline Finland & 2 & 1 & \\
\hline France & 1 & 1 & French longitudinal study of growth and nutrition (FLSGN) \\
\hline Greece & 1 & 1 & \\
\hline \multirow[t]{2}{*}{ Netherlands } & 16 & 2 & Amsterdam Growth and Health Longitudinal Study (AGHLS) \\
\hline & & & Tracking Adolescents' Individual Lives Survey (TRAILS) \\
\hline Nigeria & 1 & 1 & \\
\hline \multirow[t]{2}{*}{ Norway } & 10 & 3 & Norwegian Longitudinal Health Behaviour Study (NLHB) \\
\hline & & & Oslo Youth Study (OYS) \\
\hline Philippines & 2 & 1 & Cebu Longitudinal Health and Nutrition Study (CLHNS) \\
\hline South Africa & 2 & 1 & Birth to Twenty study (Bt20) \\
\hline Spain & 1 & 1 & \\
\hline Sweden & 3 & 3 & European Youth Heart Study (EYHS) \\
\hline \multirow[t]{2}{*}{ UK } & 4 & 2 & Health and Behaviour in Teenagers Study (HABITS) \\
\hline & & & Northern Ireland Young Hearts Project $(\mathrm{YH})$ \\
\hline \multirow[t]{10}{*}{ US } & 40 & 15 & Coronary Artery Risk Development in Young Adults Study (CARDIA) \\
\hline & & & Growing Up Today Study II (GUTS2) \\
\hline & & & Identifying Determinants of Eating and Activity (IDEA) and the Etiology of Childhood Obesity (ECHO). \\
\hline & & & lowa Bone Development Study (IBDS) \\
\hline & & & National Heart, Lung, and Blood Institute Growth and Health Study (NGHS) \\
\hline & & & National Longitudinal Study of Adolescent Health (Add Health) \\
\hline & & & National Longitudinal Survey of Youth (NLSY97) \\
\hline & & & NEXT Generation Health Study (NEXT) \\
\hline & & & Project Eating and Activity in Teens (Project EAT) (I, II \& III) \\
\hline & & & Study of Latino Adolescents at Risk for Diabetes (SOLAR) \\
\hline Total & 98 & 40 & \\
\hline
\end{tabular}

example CARDIA, with an age range of 18-30 years at baseline and the Growing Up Today Study II (GUTS2) with an age range of 9-16 years at baseline.

\section{Methods of dietary assessment}

Studies varied in method of dietary assessment. Methods used included questionnaire items $(n=18)$, food frequency questionnaires (FFQ, $n=9)$, diet history interviews $(n=3)$, dietary recalls $(n=6)$ and diet diaries $(n=4)$. As shown in Fig. 2, large studies showed less frequent use of recall and diary methods and more frequent use of FFQs compared with medium-sized and small studies.

Variation in dietary assessment method by outcome reported can also be seen from Figs. 3 and 4, below.
Studies reporting on food groups, compared to macronutrient data, more frequently show dietary assessment by questionnaires rather than other methods.

\section{Data coverage of macronutrients and food groups}

Figures 3 and 4 provide an overview of the longitudinal data available, for all macronutrients and for food groups reported on by more than five studies. Two studies could not be included in figures, due to a lack of reported information on mean age of study participants (National Longitudinal Survey of Youth (NLSY97) [24], Onimawo [25]). As noted previously, a number of studies reported on cohorts with a wide age range so that the age of study participants will vary around the mean age depicted. In the figures, studies are classified according to method of dietary assessment, presented in three 


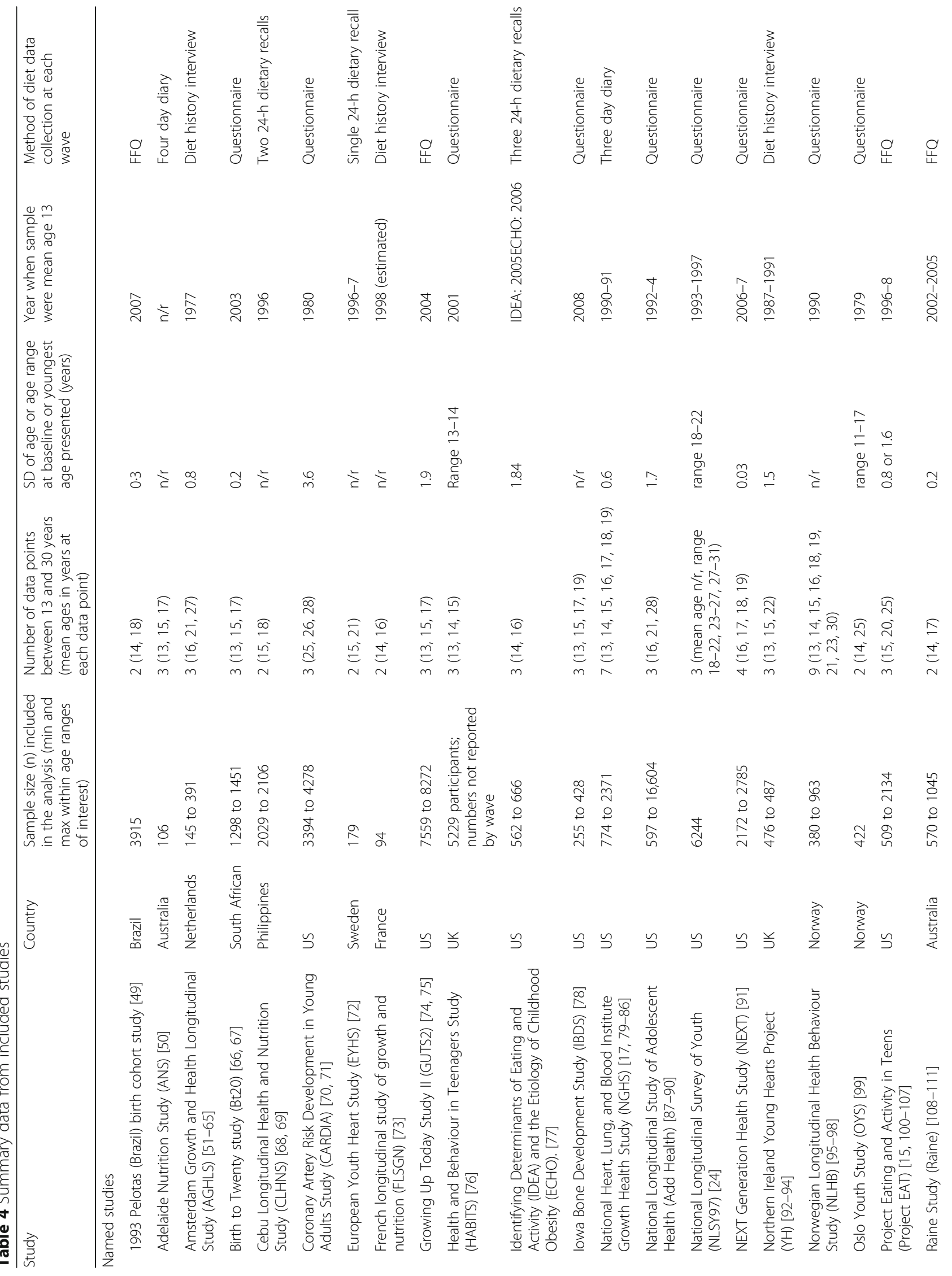




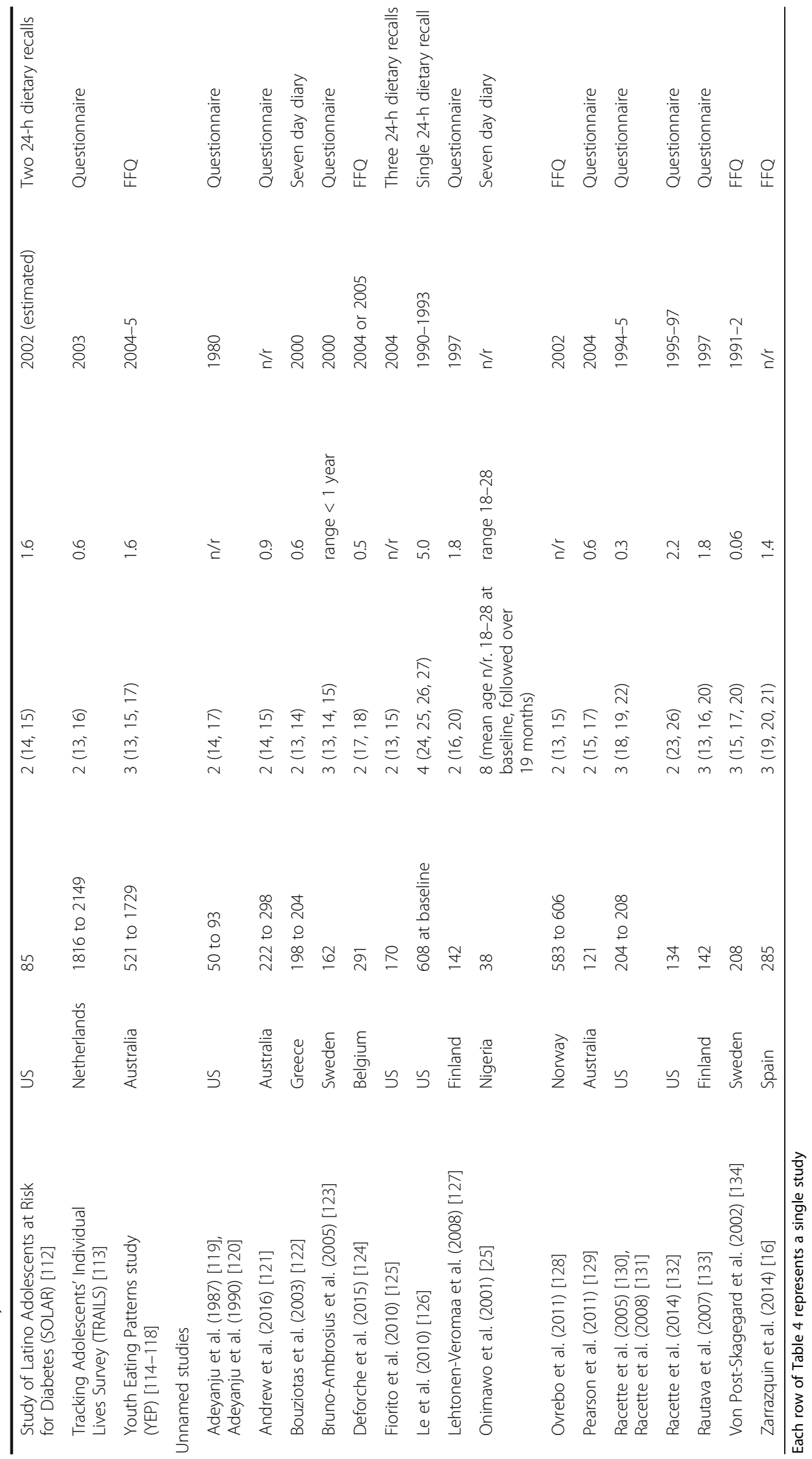




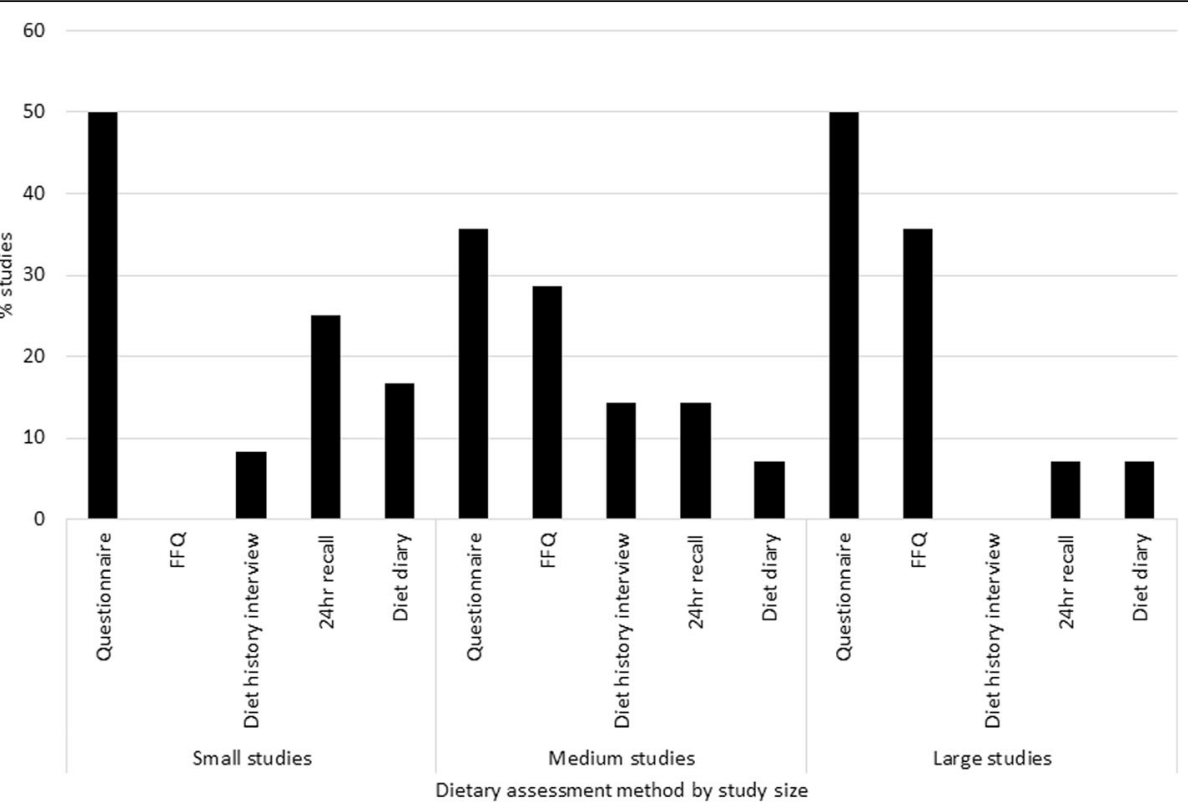

Fig. 2 Proportion of studies using each data collection method, by study size. Note: Large studies defined as >1000 participants, medium studies: $200<$ participants < 1000 and small studies: <200 participants

groups: diaries and recalls that require participants to report all food and drink consumed on one or more specific days, FFQs and diet histories that record data on habitual dietary intake over a longer time period, or targeted questionnaires, which ask respondents to report frequency of consumption of only a limited number of food items. A small number of studies $(<5$ in each case) reported on consumption of additional foods that are not included in Figs. 3 and 4. These included total grains, whole grains, bread, pasta/rice, breakfast cereals, pizza/pies/pancakes, fish, spreads/oils, cakes/ biscuits/puddings, nuts/legumes, or tea/coffee (see Additional file 1: Appendix 1 for a complete list of additional foods and food groups with references).

\section{Data coverage by age: Number and mean age of data collections}

As reported in Table 4, and also visible in Figs. 3 and 4, most studies report data from only two or three time points at which the cohort is within the age range of interest. Notable exceptions include the NGHS, for which yearly repeated data on energy intake, macronutrients as well as less frequent data on a number of food groups is reported. Repeated reporting of food group intakes is also available from the NLHB and the NEXT Generation Health Study (NEXT). Where data was reported at ages outside of our age range of interest, we have indicated this by extension of the figure lines beyond the data points shown. Figures 3 and 4 also demonstrate the preponderance of available data on both macronutrients and food groups from the adolescent years and very early twenties with few studies continuing to collect relevant data into the mid and late twenties.

\section{Discussion}

Identifying the range of available evidence to better understand changing diet through adolescence and into early adulthood is a crucial first step to inform further evidence synthesis and epidemiological analysis, and provide evidence to support appropriate targeting of dietary public health interventions. The aim of this paper was to explore how longitudinal change in diet has been conceptualised and measured between the ages of 13 and 30. To our knowledge this is the first overview of longitudinal data on food and nutrient intakes over this age range.

\section{Principal findings}

Longitudinal dietary data were reported on total energy, the three primary macronutrients (carbohydrate, fat and protein) and fibre and a small number of food groups for cohorts between the ages of 13 and 30 . While we found only seven food groups where data were reported by five or more studies, these included food groups that are of current interest to national food policies such as soft drinks, snack foods, fast food and fruits and vegetables [26, 27]. We found that the availability of data varied across the age range of interest, with considerably more studies reporting on data 


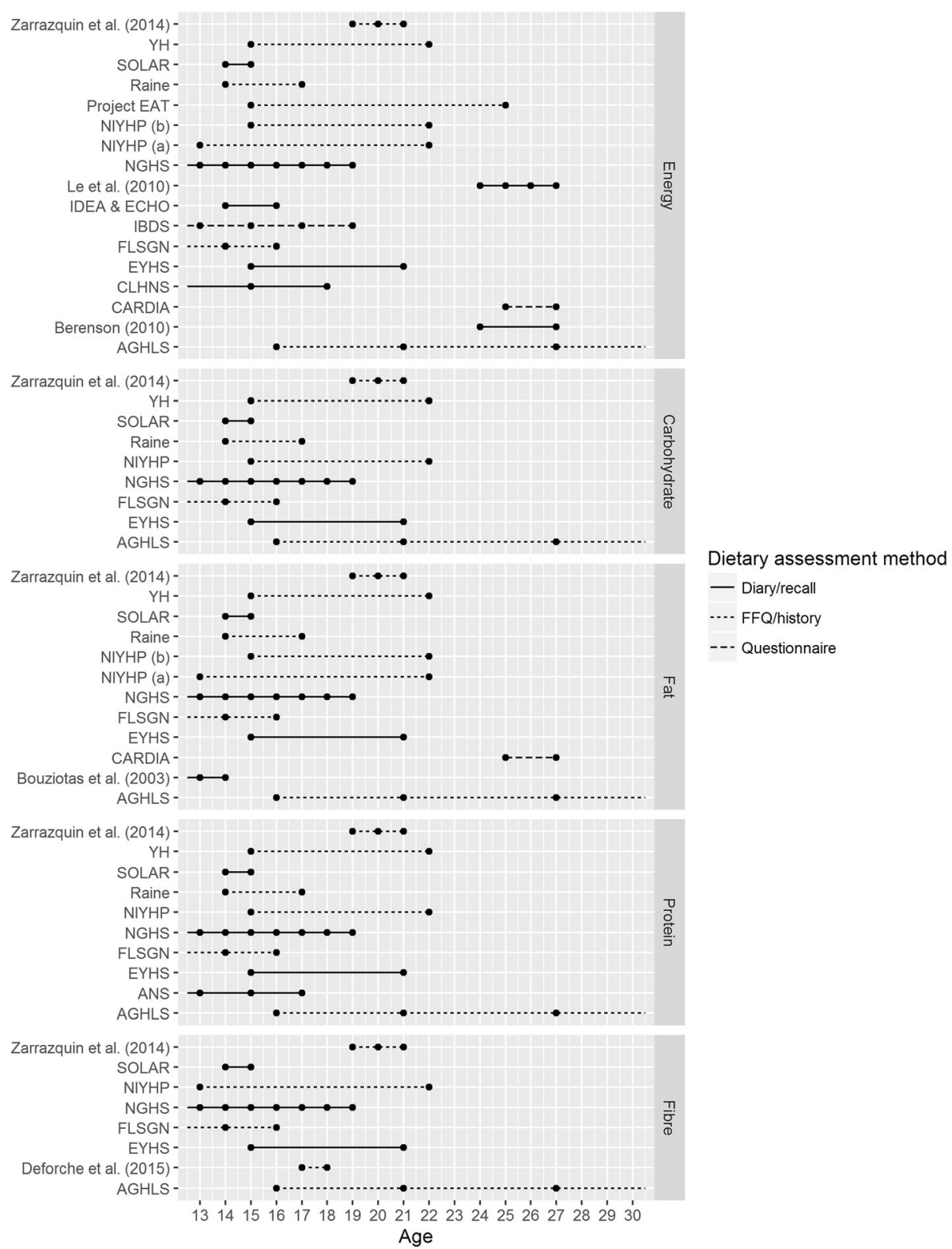

Fig. 3 Available longitudinal data on energy and macronutrient intakes, according to mean age of the cohort, between ages 13 and 30 years. Note: Data points represent diet assessment points within each study, plotted at the mean age of study participants. Lines extend beyond data points where data (collected within our date limits) is additionally reported at mean ages below 13 or above 30. See Table 3 for full versions of all study name abbreviations

from the adolescent years than data from early adulthood, and very few studies continuing beyond the early twenties. Many studies provided data at only two or three time points, providing limited opportunities to gain insight into trajectories of diet over time.

\section{Strengths and weaknesses of this scoping review}

The strength of a scoping review methodology is that it allows mapping of a heterogeneous research area and provides an overview of the data available. This is particularly useful when a body of literature has yet to be comprehensively reviewed and exhibits a large range of study designs and methodologies [20], as in this case. The review provides a comprehensive overview of published evidence on longitudinal change in diet over the period from adolescence to early adulthood across all macronutrients and food groups. However, we did not include studies that reported diet only in terms of 


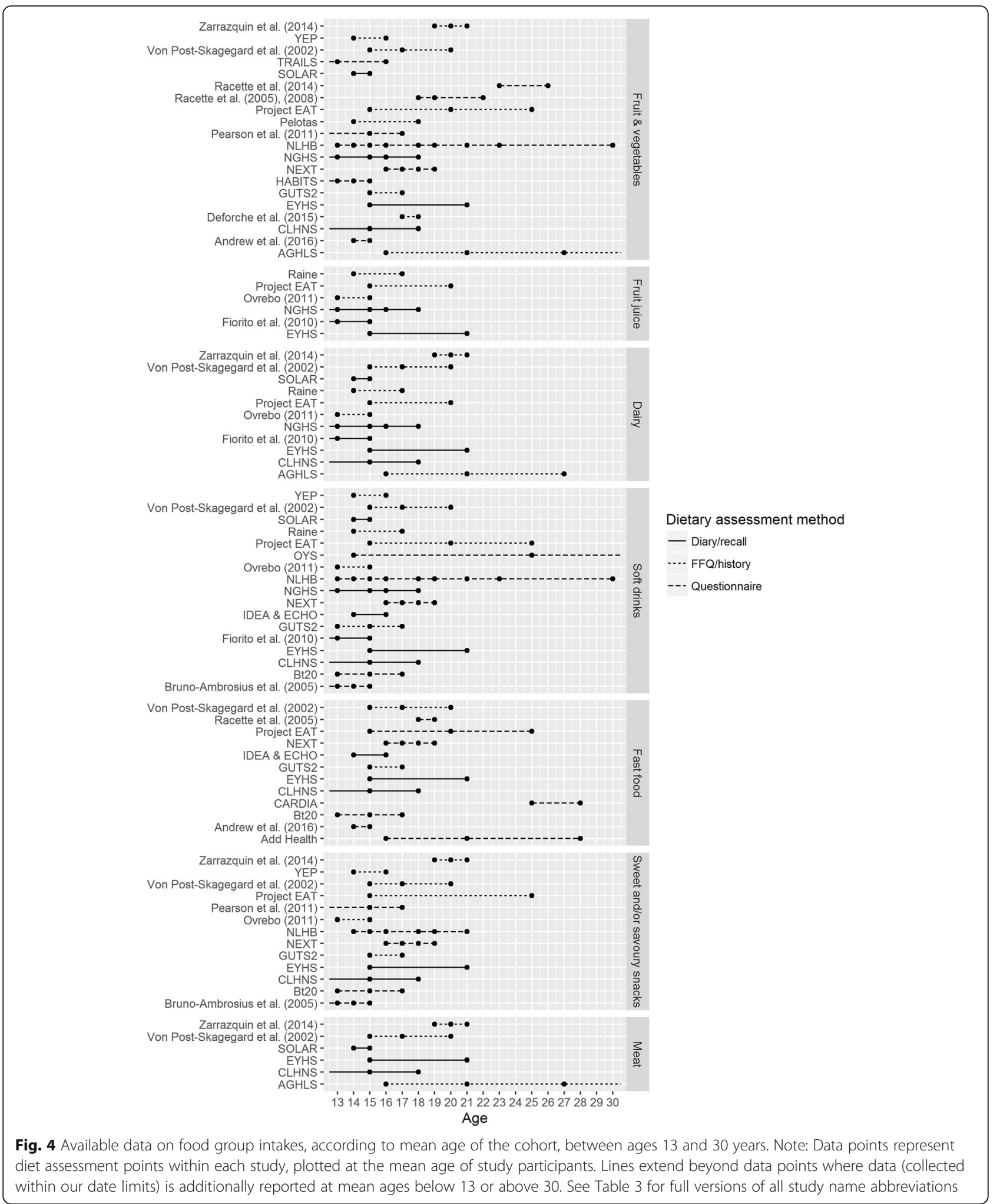

dietary intake scores or data-driven dietary patterns, due to the challenges of making comparisons between different scores or dietary patterns.
There are, in addition, several limitations that result from the nature of a scoping review. Firstly, we do not report on the results of the diet data presented; further 
work will be required to analyse and synthesise the data on individual macronutrient and food group outcomes. In addition, we did not assess the quality of the evidence presented, so that, beyond information on dietary assessment method, it is not possible from this review to judge the quality of information from a given study. A further limitation derives from our literature search. Following our aim to investigate this transition period, search terms focussed on adolescence and 'young adulthood' or 'early adulthood, hence we may have missed some studies with data available in the early adult years which did not include this terminology. This limitation is difficult to overcome. However, in our hand searching we identified only one additional study, giving us a degree of confidence that our systematic search procedure was comprehensive.

\section{Implications of the findings}

\section{Populations covered by study cohorts}

The context of the studies included in this review, in particular the period and country in which studies were situated, may affect the applicability of study findings to current dietary trajectories. In this review we restricted studies to those that collected data after 1980 and most of the studies included reported on data from the 1990s and 2000s, so data will be relatively applicable to current populations. However, there are known to be differences in diet and secular trends in diet between countries [28], and differences in physical and social environments across countries which may impact on diet trajectories, in particular between the US and Europe [29]. Since a large proportion of the studies in this review came from the US, and we found little data from low or middleincome countries, the generalizability of the data to other contexts may be limited.

\section{Methods of dietary assessment}

One of the key factors determining the quality of dietary data is the method of dietary assessment used as well as the level of compliance with data reporting among participants [30]. Studies found in this review reported use of a range of different methods which have different strengths and limitations in this age group [31-33]. The use of targeted questionnaire items is of particular concern for studying longitudinal changes in diet, since these items have often not be validated, and the lack of a comprehensive dietary assessment means that adjustment for misreporting based on energy intake or changes in overall levels of energy intake with age is not possible. Observed differences in methods of dietary assessment and data processing according to diet outcome or size of study will likely reflect differing aims and resources of the studies; many cohorts included in this review did not have a primary aim of studying longitudinal dietary data, rather, they were focussed on studying relationships between aspects of diet and anthropometric or health-related outcomes. In these large-scale cohort studies, selection of data collection instruments will be a trade-off between feasibility, acceptability, cost, validity of results and other priorities [31]. Future evidence synthesis on this topic should take account of dietary assessment method in methodological quality assessments to aid interpretation.

Future primary studies will need to consider carefully the method of diet measurement used in order to achieve valid measurement of change in dietary intake over this age range. All methods for self-reported diet data collection present limitations, frequently resulting in underreporting of total energy intake when compared to objective measures [34]. Reviews of dietary assessment methodologies used in adolescence are inconclusive as to the best method of measuring habitual intake of macronutrients and food groups among this age group [31-33]. Diet diaries have been shown to result in greater under-reporting among adolescents than adult populations, with increased underreporting with age through adolescence, and across multiple days of diary entry [32, 35]. By contrast, FFQs are characterised by low participant burden and are designed to give an indication of usual intake among participants, but show low agreement between estimated energy intake and a reference measure of total energy expenditure [33]. While no dietary assessment method is able to completely accurately assess habitual dietary intake, the use of multiple 24-h recalls may be preferred in adolescence as a compromise which achieves relatively high accuracy of data, while minimising participant burden and so increasing compliance [31, 33]. Web-based assessments, which have been shown to be comparable to interviewer-led multiple pass 24-h recalls [36], may increase compliance with and feasibility of data collection among a young and mobile population [36-38].

\section{Data coverage of macronutrients and food groups}

In this review, we identified that longitudinal dietary data were relatively frequently reported on total energy, the three primary macronutrients (carbohydrate, fat and protein) and fibre and a small number of food groups for cohorts between the ages of 13 and 30. This suggests that further systematic reviews focussing on the above macronutrients and food groups will be helpful to generate insights into the direction and magnitude of dietary changes over this period. A number of the food groups for which more data are available (for example, soft drinks) are of particular relevance to current health policy debates across many countries [39] and therefore of public health relevance to analyse further. While we did not explicitly assess variability in reporting of diet measures across papers in this study, it became apparent through the process of grouping papers according to 
food groups that, unlike with energy and macronutrients, there was considerable variation between studies in how foods were categorised and reported. This is likely to present a challenge for future systematic reviews, and further work will be required to harmonise data across studies. To aid future evidence synthesis, greater consistency in classification and reporting of food groups is recommended.

\section{Data coverage by age: Number and mean age of data collections}

We found considerably more studies reporting on data from the adolescent years than data from early adulthood, with very few studies continuing beyond the early twenties. Transition events, such as entry into the labour market, moving out of the parental home, formation of stable partner relationships, and entry to parenthood, are reported to be occurring at older ages than was seen previously, with many transitions continuing into the late-twenties [40]. Thus limited coverage of dietary data beyond the early twenties limits our ability to understand changes in diet across the adolescence to adulthood transition. Furthermore, many studies reported data at only two or three data points within our age range of interest, rather than reporting repeated longitudinal assessments over time. While such prospective data can provide information on determinants of dietary change which occur between the time points where diet is assessed, studies with more repeated measures will provide further insight into trajectories of behaviour over time, how these trajectories differ between groups of individuals and whether determinants of dietary change result in long-term trajectory modifications or only short-term changes which dissipate over time. To model individual trajectories, for example using growth modelling, requires a minimum of 4 time-points is recommended to allow enough parameters for model flexibility [41]. The findings of this scoping review suggest a need for further dietary data collection continuing into early adulthood, incorporating more frequently repeated dietary assessments to allow for diet trajectory analysis.

\section{Unanswered questions and future research}

Overall our findings indicate that data reporting on longitudinal dietary change from adolescence to early adulthood are available for several macronutrients and food groups, and further systematic reviews that focus on these macronutrients or food groups will be useful to generate understanding of the direction and magnitude of dietary changes over this period. However, this review highlights significant gaps and limitations in the data available. In particular there is a paucity of longitudinal data continuing from adolescence into the mid and late twenties and few studies that report regular follow-up of participants over more than three waves. Further data collection will thus be essential to develop a thorough understanding of trajectories in dietary behaviour across this life stage. Other papers have additionally highlighted the importance of further study of adolescent nutrition [1] and the gap in available evidence on change in dietary behaviours in early adulthood [6], suggesting that researchers are now recognising the importance of this transitional life stage.

One contributing factor in the paucity of evidence is the challenge of collecting data from individuals of this age range. Particular challenges include high levels of underreporting in this age group [42], as well as difficulties of retention of adolescents and young adults in longitudinal studies. Low retention may be related to low motivation to contribute to research among this age group, or to the difficulty of tracking individuals who are frequently relocating [43, 44]. Despite these challenges, there has been recent progress in addressing such data collection challenges through technological innovations including the use of photographic methods which can calculate food intakes automatically [45] and online dietary recall which may reduce participant burden as well as lowering data collection and processing costs [43, 46, 47]. In addition, recent developments in social media have been found useful in participant recruitment [48], and may also prove useful in tracking participants longitudinally due to consistency of social media contact information over time. Together, these advances may alleviate some of the barriers to longitudinal data collection in this age group, suggesting an opportunity for new efforts to collect and analyse dietary data and study the determinants of dietary behaviour change in this age range.

\section{Conclusion}

In this scoping review we have shown that there is limited longitudinal data available on diet between the ages of 13 and 30 . While there is some data available across the macronutrients and key food groups, data availability varies significantly by country and the methods of diet data collection used may have implications for data quality and potential for future evidence synthesis. We found little repeated longitudinal data across the adolescence to adult transition, with very little data reported beyond the early twenties. Recent advances in data collection methodology and use of social media may facilitate new data collection to allow further advances in understanding of dietary change across this age range and its determinants.

\section{Additional file}

Additional file 1: Table S1. Medline search strategy, Appendix 1. Additional foods reported. (DOCX $66 \mathrm{~kb}$ ) 


\section{Abbreviations}

Add Health: National Longitudinal Study of Adolescent Health;

AGHLS: Amsterdam Growth and Health Longitudinal Study; ANS: Adelaide Nutrition Study; Bt20: Birth to Twenty study; CARDIA: Coronary Artery Risk Development in Young Adults Study; CLHNS: Cebu Longitudinal Health and Nutrition Study; ECHO: Etiology of Childhood Obesity; EYHS: European Youth Heart Study; FFQ: Food frequency questionnaire; FLSGN: French longitudinal study of growth and nutrition; GUTS2: Growing Up Today Study II; HABITS: Health and Behaviour in Teenagers Study; IBDS: lowa Bone Development Study; IDEA: Identifying Determinants of Eating and Activity; NEXT: NEXT Generation Health Study; NGHS: National Heart, Lung, and Blood Institute Growth and Health Study; NLHB: Norwegian Longitudinal Health Behaviour Study; NLSY97: National Longitudinal Survey of Youth; OYS: Oslo Youth Study; Pelotas: 1993 Pelotas (Brazil) birth cohort study; Project EAT: Project Eating and Activity in Teens; Raine: Raine Study (The Western Australian Pregnancy Cohort); SOLAR: Study of Latino Adolescents at Risk for Diabetes; TRAILS: Tracking Adolescents' Individual Lives Survey; WHO: World Health Organization; YEP: Youth Eating Patterns study; YH: Northern Ireland Young Hearts Project

\section{Acknowledgements}

The authors would like to thank Isla Kuhn from the University of Cambridge Medical Library who provided advice and assistance with the literature searches.

\section{Funding}

The work was undertaken by the Centre for Diet and Activity Research (CEDAR), a UKCRC Public Health Research Centre of Excellence. Funding from the British Heart Foundation, Cancer Research UK, Economic and Social Research Council, Medical Research Council, the National Institute for Health Research, and the Wellcome Trust, under the auspices of the UK Clinical Research Collaboration, is gratefully acknowledged. This work was additionally supported by the Medical Research Council [Unit Programme number MC_UU_12015/7]. Tarra Penney additionally received support from the Cambridge Commonwealth Trust.

\section{Availability of data and materials}

The datasets generated during the current study are available from the corresponding author on reasonable request.

\section{Authors' contributions}

EW, KC, MW and EvS designed the study, EW performed the literature searches, EW, KC, EvS conducted title and abstract screening, EW and TP screened full texts and conducted data extraction, EW drafted the manuscript. All authors contributed to the interpretation of results and critically reviewed the manuscript. All authors read and approved the final manuscript.

\section{Competing interests}

$\mathrm{KC}$ is a director of Ridgepoint Consulting Ltd., an operational improvement consultancy. The remaining authors declare that they have no competing interests.

\section{Consent for publication}

Not applicable.

\section{Ethics approval and consent to participate}

Not applicable.

Received: 23 November 2016 Accepted: 22 April 2017

Published online: 04 May 2017

\section{References}

1. Lytle LA. Nutritional issues for adolescents. J Am Diet Assoc. 2002;102:S8-12.

2. Craigie AM, Lake AA, Kelly SA, Adamson AJ, Mathers JC. Tracking of obesityrelated behaviours from childhood to adulthood: a systematic review. Maturitas. 2011;70:266-84.

3. He FJ, Nowson CA, Lucas M, MacGregor GA. Increased consumption of fruit and vegetables is related to a reduced risk of coronary heart disease: metaanalysis of cohort studies. J Hum Hypertens England. 2007;21:717-28.
4. Aune D, Chan DSM, Lau R, Vieira R, Greenwood DC, Kampman E, et al. Dietary fibre, whole grains, and risk of colorectal cancer: systematic review and doseresponse meta-analysis of prospective studies. BMJ. 2011;343:d6617.

5. Franz MJ, Bantle JP, Beebe CA, Brunzell JD, Chiasson J-L, Garg A, et al. Evidence-based nutrition principles and recommendations for the treatment and prevention of diabetes. Diabetes Care. 2002;25:148-98.

6. Nelson MC, Story M, Larson NI, Neumark-Sztainer D, Lytle LA. Emerging adulthood and college-aged youth: an overlooked age for weight-related behavior change. Obesity. 2008;16:2205-11.

7. Viner RM, Ross D, Hardy R, Kuh D, Power C, Johnson A, et al. Life course epidemiology: recognising the importance of adolescence. J Epidemiol Community Health. 2015;69:719-20.

8. Rindfuss RR. The young adult years: diversity, structural change, and fertility. Demography. 1991;28:493-512.

9. Schwartz SJ, Zamboanga BL, Luyckx K, Meca A, Ritchie RA. Identity in emerging adulthood: reviewing the field and looking forward. Emerg Adulthood. 2013;1:96-113.

10. Draper CE, Grobler L, Micklesfield LK, Norris SA. Impact of social norms and social support on diet, physical activity and sedentary behaviour of adolescents: a scoping review. Child Care Health Dev. 2015;41:654-67.

11. El Ansari W, Stock C, Mikolajczyk RT. Relationships between food consumption and living arrangements among university students in four European countries - a cross-sectional study. Nutr J. 2012;11:28.

12. Driessen CE, Cameron AJ, Thornton LE, Lai SK, Barnett LM. Effect of changes to the school food environment on eating behaviours and/or body weight in children: a systematic review. Obes Rev. 2014;15:968-82.

13. Verplanken B, Walker I, Davis A, Jurasek M. Context change and travel mode choice: combining the habit discontinuity and self-activation hypotheses. J Environ Psychol. 2008;28:121-7.

14. Verplanken B, Roy D. Empowering interventions to promote sustainable lifestyles: testing the habit discontinuity hypothesis in a field experiment. J Environ Psychol. 2016;45:127-34.

15. Larson NI, Neumark-Sztainer DR, Story MT, Wall MM, Harnack LJ, Eisenberg ME. Fast food intake: longitudinal trends during the transition to young adulthood and correlates of intake. J Adolesc Health. 2008;43:79-86.

16. Zarrazquin I, Torres-Unda J, Ruiz F, Irazusta J, Kortajarena M, Hoyos Cillero I, et al. Longitudinal study: lifestyle and cardiovascular health in health science students. Nutr Hosp. 2014;30:1144-51.

17. Striegel-Moore RH, Thompson D, Affenito SG, Franko DL, Obarzanek E, Barton BA, et al. Correlates of beverage intake in adolescent girls: the National Heart, Lung, and Blood Institute growth and health study. J Pediatr. 2006;148:183-7.

18. Arksey H, O'Malley L. Scoping studies: towards a methodological framework. Int J Soc Res Methodol. 2005;8:19-32.

19. Levac D, Colquhoun H, O'Brien KK. Scoping studies: advancing the methodology. Implement Sci. 2010;5:69.

20. Peters MDJ, Godfrey CM, Khalil H, McInerney P, Parker D, Soares CB. Guidance for conducting systematic scoping reviews. Int J Evid Based Healthc. 2015;13:141-6.

21. Colquhoun HL, Levac D, O'Brien KK, Straus S, Tricco AC, Perrier L, et al. Scoping reviews: time for clarity in definition, methods, and reporting. J Clin Epidemiol. 2014;67:1291-4.

22. World Health Organization. Maternal, newborn, child and adolescent health: Adolescent development [Internet]. 2016. http://www.who.int/maternal_ child_adolescent/topics/adolescence/dev/en/. Accessed 22 Nov 2016.

23. Arnett JJ. Emerging adulthood: a theory of development from the late teens through the twenties. Am Psychol. 2000;55:469-80.

24. Jayawardene WP, Torabi MR, Lohrmann DK. Exercise in young adulthood with simultaneous and future changes in fruit and vegetable intake. J Am Coll Nutr. 2016;35:59-67.

25. Onimawo IA. Inter-individual variations in energy and nutrient intake among young Nigerian adults. Ecol Food Nutr. 2001;40:127-41.

26. Mytton OT, Clarke D, Rayner M. Taxing unhealthy food and drinks to improve health. BMJ. 2012;344:e2931.

27. Department for Education. School Food Standards: A practical guide for schools their cooks and caterers. London; 2015. http://www.schoolfoodplan. com/wp-content/uploads/2015/01/School-Food-Standards-Guidance-FINALV3.pdf. Accessed 22 Nov 2016

28. Vereecken C, Pedersen TP, Ojala K, Krølner R, Dzielska A, Ahluwalia N, et al. Fruit and vegetable consumption trends among adolescents from 2002 to 2010 in 33 countries. Eur J Pub Health. 2015;25:16-9. 
29. Caspi CE, Sorensen G, Subramanian SV, Kawachi I. The local food environment and diet: a systematic review. Health Place. 2012;18:1172-87.

30. Magarey A, Watson J, Golley RK, Burrows T, Sutherland R, McNaughton S $a$, et al. Assessing dietary intake in children and adolescents: considerations and recommendations for obesity research. Int J Pediatr Obes. 2011;6:2-11.

31. Rankin D, Hanekom SM, Wright HH, Maclntyre UE. Dietary assessment methodology for adolescents: a review of reproducibility and validation studies. S Afr J Clin Nutr. 2010;23:65-74.

32. Collins CE, Watson J, Burrows T. Measuring dietary intake in children and adolescents in the context of overweight and obesity. Int J Obes. 2010;34:1103-15.

33. Burrows TL, Martin RJ, Collins CE. A systematic review of the validity of dietary assessment methods in children when compared with the method of doubly labeled water. J Am Diet Assoc. 2010:110:1501-10.

34. Subar AF, Freedman LS, Tooze JA, Kirkpatrick SI, Boushey C, Neuhouser ML, et al. Addressing current criticism regarding the value of self-report dietary data. J Nutr. 2015;145:2639-45.

35. Livingstone MBE, Robson PJ. Measurement of dietary intake in children. Proc Nutr Soc. 2000;59:279-93.

36. Bradley J, Simpson E, Poliakov I, Matthews JNS, Olivier P, Adamson AJ, et al. Comparison of INTAKE24 (an online 24-h dietary recall tool) with interviewer-led 24-h recall in 11-24 year-old. Nutrients. 2016:8:358.

37. Albar SA, Alwan NA, Evans CEL, Greenwood DC, Cade JE. Agreement between an online dietary assessment tool (myfood24) and an interviewer-administered 24-h dietary recall in British adolescents aged 11-18 years. Br J Nutr. 2016;115:1678-86.

38. Boushey C, Kerr D, Wright J, Lutes K, Ebert D, Delp E. Use of technology in children's dietary assessment. Eur J Clin Nutr. 2009;63:1-15.

39. World Health Organization. WHO urges global action to curtail consumption and health impacts of sugary drinks. 2016. http://www.who.int/mediacentre/ news/releases/2016/curtail-sugary-drinks/en/. Accessed 27 Jan 2017.

40. Buchmann MC, Kriesi I. Transition to adulthood in Europe. Annu Rev Sociol. 2011;37:481-503

41. Muthen LK. Mplus discussion: Timepoints. http://www.statmodel.com/ discussion/messages/14/20.html\#POST16727. Accessed 24 Aug 2016.

42. Livingstone MB, Robson PJ, Wallace JMW. Issues in dietary intake assessment of children and adolescents. Br J Nutr. 2004;92:S213-22.

43. Foster $E$, Adamson A. Challenges involved in measuring intake in early life: focus on methods. Proc Nutr Soc. 2014;73:201-9.

44. Faden VB, Day NL, Windle M, Windle R, Grube JW, Molina BSG, et al. Collecting longitudinal data through childhood, adolescence, and young adulthood: methodological challenges. Alcohol Clin Exp Res. 2004;28:330-40.

45. Martin CK, Nicklas T, Gunturk B, Correa JB, Allen HR, Champagne C. Measuring food intake with digital photography. J Hum Nutr Diet. 2014;27:72-81.

46. Adamson AJ, Baranowski T. Developing technological solutions for dietary assessment in children and young people. J Hum Nutr Diet. 2014;27:1-4.

47. Simpson E, Delve J, Poliakov I, Foster E, Jackson D, Comber R, et al. Iterative development of an online dietary recall tool, INTAKE24. Proc Nutr Soc. 2015;74:E117.

48. Leonard A, Hutchesson M, Patterson A, Chalmers K, Collins C. Recruitment and retention of young women into nutrition research studies: practical considerations. Trials. 2014;15:23.

49. Buffarini R, Muniz LC, Barros AJD, Araújo CL, Gonçalves H, Menezes AM, et al. Stability and change in fruit and vegetable intake of Brazilian adolescents over a 3-year period: 1993 Pelotas birth cohort. Public Health Nutr. 2015;19: 386-92.

50. Magarey AM, Boulton TJC, Chatterton BE, Schultz C, Nordin BEC. Familial and environmental influences on bone growth from 11-17 years. Acta Paediatr. 1999:88:1204-10.

51. Boon N, Koppes LLJ, Saris WHM, Van Mechelen W. The relation between calcium intake and body composition in a Dutch population: the Amsterdam growth and health longitudinal study. Am J Epidemiol. 2005; $162: 27-32$

52. Kemper HCG, Post GB, Welten DC, van Mechelen W, Twisk JWR. What are the effects of calcium intake on bone health in young males and females analysis of data from the Amsterdam growth and health longitudinal study. Acta Kinesiol Univ Tartu. 2001:6:57-74

53. Post B, Kemper HC, Storm-Van EL. Longitudinal changes in nutritional habits of teenagers: differences in intake between schooldays and weekend days. Br J Nutr. 1987;57:161-76.
54. Post GB, Kemper HCG. Nutrient intake and biological maturation during adolescence. The Amsterdam growth and health longitudinal study. Eur J Clin Nutr. 1993;47:400-8.

55. Post GB, Kemper HCG, Twisk J, van Mechelen W. The association between dietary patterns and cardio vascular disease risk indicators in healthy youngsters: results covering fifteen years of longitudinal development. Eur J Clin Nutr. 1997:51:387-93.

56. Post GB, de Vente W, Kemper HCG, Twisk JWR. Longitudinal trends in and tracking of energy and nutrient intake over 20 years in a Dutch cohort of men and women between 13 and 33 years of age: the Amsterdam growth and health longitudinal study. Br J Nutr. 2001;85:375-85.

57. Twisk JWR, Staal BJ, Brinkman MN, Kemper HCG, van Mechelen W. Tracking of lung function parameters and the longitudinal relationship with lifestyle. Eur Respir J. 1998;12:627-34.

58. Twisk JWR, Kemper HCG, Mellenbergh GJ, van Mechelen W, Post GB. Relation between the longitudinal development of lipoprotein levels and lifestyle parameters during adolescence and young adulthood. Ann Epidemiol. 1996;6:246-56.

59. Twisk JW, Kemper HC, van Mechelen W, Post GB. Which lifestyle parameters discriminate high-from low-risk participants for coronary heart disease risk factors. Longitudinal analysis covering adolescence and young adulthood. J Cardiovasc Risk. 1997:4:393-400.

60. Twisk JWR, Kemper HCG, van Mechelen W, Post GB. Clustering of risk factors for coronary heart disease: the longitudinal relationship with lifestyle. Ann Epidemiol. 2001;11:157-65.

61. Uijtdewilligen L, Twisk JWR, Chinapaw MJM, Koppes LLJ, van Mechelen W, Singh AS. Longitudinal person-related determinants of physical activity in young adults. Med Sci Sports Exerc. 2014;46:529-36.

62. van de Laar RJJ, Stehouwer CDA, van Bussel BCT, Prins MH, Twisk JWR, Ferreira I. Adherence to a Mediterranean dietary pattern in early life is associated with lower arterial stiffness in adulthood: the Amsterdam growth and health longitudinal study. J Intern Med. 2013;273:79-93.

63. van de Laar RJJ, Stehouwer CDA, van Bussel BCT, te Velde SJ, Prins $\mathrm{MH}$, Twisk JWR, et al. Lower lifetime dietary fiber intake is associated with carotid artery stiffness: the Amsterdam growth and health longitudinal study. Am J Clin Nutr. 2012:96:14-23.

64. Welten DC, Kemper HCG, Post GB, Van Staveren WA, Twisk JWR. Longitudinal development and tracking of calcium and dairy intake from teenager to adult. Eur J Clin Nutr. 1997;51:612-8.

65. Welten DC, Kemper HCG, Post GB, van Mechelen W, Twisk J, Lips P, et al. Weight-bearing activity during youth is a more important factor for peak bone mass than calcium intake. J Bone Miner Res. 1994;9:1089-96.

66. Feeley $A B$, Musenge $E$, Pettifor JM, Norris SA. Investigation into longitudinal dietary behaviours and household socio-economic indicators and their association with BMI Z-score and fat mass in South African adolescents: the birth to twenty (Bt20) cohort. Public Health Nutr. 2012;16:693-703.

67. Feeley A, Musenge E, Pettifor JM, Norris SA. Changes in dietary habits and eating practices in adolescents living in urban South Africa: the birth to twenty cohort. Nutrition. 2012;28:e1-6.

68. Adair LS, Popkin BM. Are child eating patterns being transformed globally? Obes Res. 2005;13:1281-99.

69. Eckhardt CL, Suchindran C, Gordon-Larsen P, Adair LS. The association between diet and height in the postinfancy period changes with age and socioeconomic status in Filipino youths. J Nutr. 2005;135:2192-8.

70. Bild DE, Sholinsky P, Smith DE, Lewis CE, Hardin JM, Burke GL. Correlates and predictors of weight loss in young adults: the CARDIA study. Int J Obes. 1996;20:47-55.

71. Duffey KJ, Gordon-Larsen P, Jacobs DR Jr, Williams OD, Popkin BM. Differential associations of fast food and restaurant food consumption with 3-y change in body mass index: the coronary artery risk development in young adults study. Am J Clin Nutr. 2007:85:201-8.

72. Patterson E, Wärnberg J, Kearney J, Sjöström M. The tracking of dietary intakes of children and adolescents in Sweden over six years: the European youth heart study. Int J Behav Nutr Phys Act. 2009;6

73. Deheeger M, Bellisle F, Rolland-Cachera MF. The French longitudinal study of growth and nutrition: data in adolescent males and females. J Hum Nutr Diet. 2002;15:429-38.

74. Falbe J, Willett WC, Rosner B, Gortmaker SL, Sonneville KR, Field AE. Longitudinal relations of television, electronic games, and digital versatile discs with changes in diet in adolescents. Am J Clin Nutr. 2014;100:1173-81. 
75. Field AE, Sonneville KR, Falbe J, Flint A, Haines J, Rosner B, et al. Association of sports drinks with weight gain among adolescents and young adults. Obesity. 2014;22:2238-43.

76. van Jaarsveld CHM, Fidler JA, Simon AE, Wardle J. Persistent impact of pubertal timing on trends in smoking, food choice, activity, and stress in adolescence. Psychosom Med. 2007;69:798-806.

77. Laska MN, Murray DM, Lytle LA, Harnack LJ. Longitudinal associations between key dietary behaviors and weight gain over time: transitions through the adolescent years. Obesity. 2012;20:118-25.

78. Kwon S, Janz KF, Letuchy EM, Burns TL, Levy SM. Active lifestyle in childhood and adolescence prevents obesity development in young adulthood. Obesity. 2015;23:2462-9.

79. Affenito SG, Thompson DR, Barton BA, Franko DL, Daniels SR, Obarzanek E, et al. Breakfast consumption by African-American and white adolescent girls correlates positively with calcium and fiber intake and negatively with body mass index. J Am Diet Assoc. 2005;105:938-45.

80. Affenito SG, Thompson DR, Franko DL, Striegel-Moore RH, Daniels SR, Barton BA et al. Longitudinal assessment of micronutrient intake among African-American and white girls: the National Heart, Lung, and Blood Institute growth and health study. J Am Diet Assoc. 2007;107:1113-23.

81. Barton BA, Eldridge AL, Thompson D, Affenito SG, Striegel-Moore RH, Franko DL, et al. The relationship of breakfast and cereal consumption to nutrient intake and body mass index: the National Heart, Lung, and Blood Institute growth and health study. J Am Diet Assoc. 2005;105:1383-9.

82. Franko DL, Albertson AM, Thompson DR, Barton BA. Cereal consumption and indicators of cardiovascular risk in adolescent girls. Public Health Nutr. 2011;14:584-90

83. Kronsberg SS, Obarzanek E, Affenito SG, Crawford PB, Sabry ZI, Schmidt M, et al. Macronutrient intake of black and white adolescent girls over 10 years: the NHLBI growth and health study. J Am Diet Assoc. 2003;103:852-60.

84. Moore LL, Singer MR, Qureshi MM, Bradlee ML, Daniels SR. Food group intake and micronutrient adequacy in adolescent girls. Nutrients. 2012;4:1692-708.

85. White J, Jago R, Thompson JL. Dietary risk factors for the development of insulin resistance in adolescent girls: a 3-year prospective study. Public Health Nutr. 2014;17:361-8.

86. Striegel-Moore RH, Thompson DR, Affenito SG, Franko DL, Barton BA, Schreiber GB, et al. Fruit and vegetable intake: Few adolescent girls meet national guidelines. Prev Med (Baltim). 2006;42:223-8.

87. Gordon-Larsen P, Guilkey DK, Popkin BM. An economic analysis of community-level fast food prices and individual-level fast food intake: a longitudinal study. Health Place. 2011;17:1235-41.

88. Harris KM, Gordon-Larsen P, Chantala K, Udry JR. Longitudinal trends in race/ethnic disparities in leading health indicators from adolescence to young adulthood. Arch Pediatr Adolesc Med. 2006;160:74-81.

89. Nelson MC, Gordon-Larsen P, North KE, Adair LS. Body mass index gain, fast food, and physical activity: effects of shared environments over time. Obesity. 2006:14:701-9.

90. Niemeier HM, Raynor HA, Lloyd-Richardson EE, Rogers ML, Wing RR. Fast food consumption and breakfast skipping: predictors of weight gain from adolescence to adulthood in a nationally representative sample. J Adolesc Health. 2006;39:842-9.

91. Lipsky LM, Haynie DL, Liu D, Chaurasia A, Gee B, Li K, et al. Trajectories of eating behaviors in a nationally representative cohort of U.S. adolescents during the transition to young adulthood. Int J Behav Nutr Phys Act. 2015;12:138

92. Boreham C, Robson PJ, Gallagher AM, Cran GW, Savage JM, Murray LJ. Tracking of physical activity, fitness, body composition and diet from adolescence to young adulthood: the young Hearts project, Northern Ireland. Int J Behav Nutr Phys Act. 2004;1

93. Gallagher AM, Robson PJ, Livingstone MBE, Cran GW, Strain JJ, Murray $L J$, et al. Tracking of energy and nutrient intakes from adolescence to young adulthood: the experiences of the young Hearts project, Northern Ireland. Public Health Nutr. 2006;9:1027-34.

94. McCourt HJ, Draffin CR, Woodside JV, Cardwell CR, Young IS, Hunter SJ, et al. Dietary patterns and cardiovascular risk factors in adolescents and young adults: the Northern Ireland young Hearts project. Br J Nutr. 2014;112:1685-98.

95. Lien N, Jacobs DR, Klepp K-I. Exploring predictors of eating behaviour among adolescents by gender and socio-economic status. Public Health Nutr. 2002;5:671-81.
96. Lien N, Lytle L a, Klepp K-I. Stability in consumption of fruit, vegetables, and sugary foods in a cohort from age 14 to age 21. Prev Med (Baltim). 2001;33:217-26.

97. Thuen F, Breivik K, Wold B, Ulveseter G. Growing up with one or both parents: the effects on physical health and health-related behavior through adolescence and into early adulthood. J Divorce Remarriage. 2015;56:451-74

98. Wiium N, Breivik K, Wold B. Growth trajectories of health behaviors from adolescence through young adulthood. Int J Environ Res Public Health. 2015;12:13711-29.

99. Kvaavik E, Andersen LF, Klepp K-I. The stability of soft drinks intake from adolescence to adult age and the association between long-term consumption of soft drinks and lifestyle factors and body weight. Public Health Nutr. 2005:8:149-57.

100. Arcan C, Neumark-Sztainer D, Hannan P, van den Berg P, Story M, Larson N. Parental eating behaviours, home food environment and adolescent intakes of fruits, vegetables and dairy foods: longitudinal findings from project EAT. Public Health Nutr. 2007;10:1257-65.

101. Bauer KW, Larson NI, Nelson MC, Story M, Neumark-Sztainer D. Fast food intake among adolescents: secular and longitudinal trends from 1999 to 2004. Prev Med (Baltim). [Internet]. Elsevier Inc. 2009;48:284-7.

102. Burgess-Champoux TL, Larson NI, Neumark-Sztainer DR, Hannan PJ, Story MT. Longitudinal and secular trends in adolescent whole-grain consumption, 1999-2004. Am J Clin Nutr. 2010;91:154-9.

103. Goldschmidt AB, Wall MM, Choo T-HJ, Larson NI, Neumark-Sztainer D. Mediators involved in the relation between depressive symptoms and weight status in female adolescents and young adults. Int J Obes. 2015;39:1027-9.

104. Larson NI, Neumark-Sztainer D, Harnack L, Wall M, Story M, Eisenberg ME. Calcium and dairy intake: longitudinal trends during the transition to young adulthood and correlates of calcium intake. J Nutr Educ Behav. 2009;41:254-60.

105. Larson NI, Neumark-Sztainer D, Hannan PJ, Story M. Trends in adolescent fruit and vegetable consumption, 1999-2004. Am J Prev Med. 2007;32:147-50.

106. Nelson MC, Neumark-Sztainer D, Hannan PJ, Story M. Five-year longitudinal and secular shifts in adolescent beverage intake: findings from project EAT (eating among teens)-II. J Am Diet Assoc. 2009;109:308-12.

107. Quick V, Wall M, Larson N, Haines J, Neumark-Sztainer D. Personal, behavioral and socio-environmental predictors of overweight incidence in young adults: 10-yr longitudinal findings. Int J Behav Nutr Phys Act. 2013;10:37.

108. O'Sullivan TA, Bremner AP, Mori TA, Beilin LJ, Wilson C, Hafekost K, et al. Regular fat and reduced fat dairy products show similar associations with markers of adolescent cardiometabolic health. Nutrients. 2016;8:22.

109. Parker CE, Vivian WJ, Oddy WH, Beilin LJ, Mori TA, O'Sullivan TA. Changes in dairy food and nutrient intakes in Australian adolescents. Nutrients. 2012;4: 1794-811.

110. Black LJ, Allen KL, Jacoby P, Trapp GS, Gallagher CM, Byrne SM, et al. Low dietary intake of magnesium is associated with increased externalising behaviours in adolescents. Public Health Nutr. 2015;18:1824-30.

111. Black $L$, Burrows $S A$, Jacoby $P$, Oddy WH, Beilin $\sqcup$, Ping-Delfos WCS, et al. Vitamin D status and predictors of serum 25-hydroxyvitamin D concentrations in Western Australian adolescents. Br J Nutr. 2014;112:1154-62.

112. Davis JN, Alexander KE, Ventura EE, Toledo-Corral CM, Goran MI. Inverse relation between dietary fiber intake and visceral adiposity in overweight Latino youth. Am J Clin Nutr. 2009;90:1160-6.

113. de Winter AF, Visser $L$, Verhulst FC, Vollebergh WA, Reijneveld SA. Longitudinal patterns and predictors of multiple health risk behaviors among adolescents: the TRAILS study. Prev Med (Baltim). 2016;84:76-82.

114. Pearson N, Ball K, Crawford D. Mediators of longitudinal associations between television viewing and eating behaviours in adolescents. Int J Behav Nutr Phys Act. 2011:8:23.

115. Pearson N, Ball K, Crawford D. Predictors of changes in adolescents' consumption of fruits, vegetables and energy-dense snacks. $\mathrm{Br} J$ Nutr. 2011;105:795-803.

116. Stephens LD, McNaughton SA, Crawford D, Ball K. Longitudinal predictors of frequent vegetable and fruit consumption among socio-economically disadvantaged Australian adolescents. Appetite. 2014;78:165-71.

117. Stephens LD, McNaughton SA, Crawford D, Ball K. Predictors of high-energy foods and beverages: a longitudinal study among socio-economically disadvantaged adolescents. Public Health Nutr. 2014;17:324-37.

118. Stephens LD, McNaughton SA, Crawford D, Ball K. Socio-economic differences in predictors of frequent dairy food consumption among Australian adolescents: a longitudinal study. Public Health Nutr. 2015;18:3326-36. 
119. Adeyanju M, Creswell WH. The relationship among attitudes, behaviors, and biomedical measures of adolescents "at risk" for cardiovascular disease. J Sch Health. 1987;57:326-31.

120. Adeyanju M. Adolescent health status, behaviors and cardiovascular disease. Adolescence. 1990;25:155-69.

121. Andrew R, Tiggemann M, Clark L. Predictors and health-related outcomes of positive body image in adolescent girls: a prospective study. Dev Psychol. 2016;52:463-74.

122. Bouziotas $C$, Koutedakis Y. A three year study of coronary heart disease risk factors in Greek adolescents. Pediatr Exerc Sci. 2003;15:9-18.

123. Bruno-Ambrosius K, Swanholm G, Twetman S. Eating habits, smoking and toothbrushing in relation to dental caries: a 3-year study in Swedish female teenagers. Int J Paediatr Dent. 2005;15:190-6.

124. Deforche B, Van Dyck D, Deliens T, De Bourdeaudhuij I. Changes in weight, physical activity, sedentary behaviour and dietary intake during the transition to higher education: a prospective study. Int J Behav Nutr Phys Act. 2015;12:16.

125. Fiorito LM, Marini M, Mitchell DC, Smiciklas-Wright H, Birch LL. Girls' early sweetened carbonated beverage intake predicts different patterns of beverage and nutrient intake across childhood and adolescence. J Am Diet Assoc. 2010;110:543-50.

126. Le Y-CL, Rahman M, Berenson AB. Perceived weight gain as a correlate of physical activity and energy intake among white, black, and Hispanic reproductive-aged women. J Women's Heal. 2010;19:1987-93.

127. Lehtonen-Veromaa M, Möttönen T, Leino A, Heinonen OJ, Rautava E, Viikari J. Prospective study on food fortification with vitamin $\mathrm{D}$ among adolescent females in Finland: minor effects. Br J Nutr. 2008;100:418-23.

128. Øvrebø EM. Food habits of school pupils in Tromso, Norway, in the transition from 13 to 15 years of age. Int J Consum Stud. 2011;35:520-8.

129. Pearson N, Salmon J, Campbell K, Crawford D, Timperio A. Tracking of children's body-mass index, television viewing and dietary intake over fiveyears. Prev Med (Baltim). 2011;53:268-70.

130. Racette SB, Deusinger SS, Strube MJ, Highstein GR, Deusinger RH. Weight changes, exercise, and dietary patterns during freshman and sophomore years of college. J Am Coll Heal. 2005;53:245-51.

131. Racette SB, Deusinger SS, Strube MJ, Highstein GR, Deusinger RH. Changes in weight and health behaviors from freshman through senior year of college. J Nutr Educ Behav. 2008;40:39-42.

132. Racette SB, Inman CL, Clark BR, Royer NK, Steger-May K, Deusinger SS. Exercise and Cardiometabolic risk factors in graduate students: a longitudinal, Observational, Study. J Am Coll Heal. 2014;62:47-56.

133. Rautava E, Lehtonen-Veromaa M, Kautiainen H, Kajander S, Heinonen OJ, Viikari J, et al. The reduction of physical activity reflects on the bone mass among young females: a follow-up study of 142 adolescent girls. Osteoporos Int. 2007;18:915-22.

134. von Post-Skagegård M, Samuelson G, Karlström B, Mohsen R, Berglund L, Bratteby L-E. Changes in food habits in healthy Swedish adolescents during the transition from adolescence to adulthood. Eur J Clin Nutr. 2002;56:532-8.

\section{Submit your next manuscript to BioMed Central and we will help you at every step:}

- We accept pre-submission inquiries

- Our selector tool helps you to find the most relevant journal

- We provide round the clock customer support

- Convenient online submission

- Thorough peer review

- Inclusion in PubMed and all major indexing services

- Maximum visibility for your research

Submit your manuscript at www.biomedcentral.com/submit

) Biomed Central 